\title{
Emoções, "stress", ansiedade e "coping": estudo qualitativo com treinadores de nível internacional
}

CDD. 20.ed. 796.011

796.073

\author{
Cláudia DIAS* \\ José Fernando CRUZ ${ }^{* *}$ \\ António Manuel FONSECA* \\ ${ }^{*}$ Faculdade de Des- \\ porto, Universidade do \\ Porto - Portugal. \\ **Escola de Psicologia, \\ Universidade do Minho \\ - Portugal.
}

\section{Resumo}

A influência dos fatores e processos psicológicos no desempenho desportivo dos atletas está, de uma forma geral, amplamente demonstrada; todavia, poucas investigações procuraram estudar esta relação nos treinadores. Neste sentido, empregando uma entrevista semi-estruturada, a presente investigação procurou, junto de seis treinadores de elite com idades compreendidas entre os 55 e os 63 anos $(M=59 \pm$ 3,03 ) de diversas modalidades, identificar as características/competências psicológicas mais importantes para o sucesso desportivo, as principais fontes de "stress" e ansiedade experienciadas e as estratégias de "coping" a que recorriam em situações estressantes e/ou problemáticas, adicionalmente, pretendeu explorar o papel de outras emoções no seu desempenho. Os resultados revelaram que: 1) a motivação era uma das competências/características psicológicas percepcionadas pelos treinadores como mais importantes para o sucesso; 2) as principais fontes de "stress" estavam relacionadas com preocupações com o desempenho dos atletas, sendo comuns a diferentes modalidades; 3 ) os treinadores recorriam a diversas estratégias de "coping" em simultâneo, geralmente adaptativas; e 4) para além da ansiedade, outras emoções, positivas e negativas, pareciam influenciar o desempenho dos treinadores.

Unitermos: "Stress"; Ansiedade; "Coping"; Emoções; Treinadores; Estudo qualitativo.

\section{Introdução}

Embora um número considerável de investigações se tenha vindo a preocupar com a investigação sistemática da influência dos fatores e processos psicológicos no desempenho desportivo, a grande maioria das investigaçôes tem-se centralizado nos atletas. $\mathrm{O}$ mesmo nível de interesse não tem sido devotado a outras populações, designadamente os treinadores. Com efeito, não obstante estes serem sujeitos a exigências competitivas similares às dos atletas - sendo, por exemplo, obrigados a lidar com as elevadas expectativas neles depositadas e a tomarem importantes decisóes sob pressão, enquanto são sujeitos a um intenso e nem sempre justo escrutínio público - os treinadores raramente foram encarados, no palco desportivo, como o ator principal (Giges, PetiTPAS \& VernacChia, 2004; Gould, Guinan, GreEnleaf \& Chung, 2002).

Corroborando esta afirmação, torna-se interessante constatar que embora alguns investigadores se tenham preocupado em identificar os fatores, características e/ou competências psicológicas que os treinadores consideram mais importantes para o sucesso dos atletas (e.g., Gould et al., 2002; Gould, Hodge, Peterson \& Petlichkoff, 1987), sabemos muito pouco sobre as características psicológicas mais relevantes para o sucesso dos próprios treinadores.

Um dos raros estudos que, ainda que indiretamente, se debruçou sobre esta questão, foi realizado por Gould et al. (2002) junto de 46 treinadores olímpicos. Nesta investigação, para além de identificarem variáveis que sentiam ter influenciado o desempenho dos seus atletas, os participantes também se pronunciaram relativamente às variáveis que, na sua opinião, tinham influenciado a sua eficácia nos Jogos Olímpicos de Atlanta (1996) e Nagano (1998). A análise dos resultados mostrou que os treinadores que alteraram de forma significativa os seus comportamentos de treino, que foram incapazes de estabelecer uma relação de confiança com os seus 
atletas, ou que não conseguiram lidar com situações de crise, possuíam uma percepção negativa da sua atuação durante as referidas competições. Em contraste, aqueles que conseguiram criar uma relação de confiança e credibilidade com os atletas, que se mantiveram calmos sob pressão, e que tomaram decisões justas mas assertivas, acreditavam ter sido eficazes; outros aspectos relevantes para esta percepção de eficácia incluíam a capacidade de promover um ambiente positivo (e.g., participando em exercícios de "team building1" com os atletas, assegurando uma "química" positiva e coesão entre os membros do "staff" técnico), serem responsáveis pela seleção da equipe, possuírem expectativas realistas relativamente aos seus atletas e adotarem um plano ou rotina competitiva. Mais recentemente, THELWELL, WESTON, GreENlees e Hutchings (2008) entrevistaram 13 treinadores de elite relativamente ao uso de quatro competências psicológicas: formulação de objetivos, relaxamento, visualização mental e diálogo interno ("self-talk"). A análise das entrevistas revelou que todos os treinadores do presente estudo recorriam a uma ou mais das competências psicológicas examinadas, mas a visualização mental e diálogo interno ("selftalk") foram citadas mais frequentemente do que a formulação de objetivos ou o relaxamento.

Adicionalmente, nos últimos anos parece existir um interesse mais acentuado em examinar a experiência dos treinadores com o "stress" e a ansiedade, quer no que respeita à identificação das principais fontes de "stress" nesta população (e.g., Frey, 2007; Sullivan \& NASHMAN, 1993; WANG \& RAMSEY, 1998), quer no referente à determinação das estratégias de "coping" utilizadas para lidar com essas fontes de "stress" (e.g., FreY, 2007).

Numa investigação realizada por Sullivan e NASHMAN (1993) com 10 treinadores olímpicos, por exemplo, entre as principais fontes de "stress" experienciadas por treinadores durante os Jogos Olímpicos de Barcelona (1992) incluíam-se a seleção dos atletas, a representação do país, tempo de preparação insuficiente, pressões dos mídia e o afastamento da família. Paralelamente, WANG e RAMSEY (1998) concluíram que, em treinadores em início de carreira, as principais fontes de "stress" estavam relacionadas com o domínio das competências de comunicação necessárias para o estabelecimento de uma relação positiva com os atletas, o estabelecimento de uma atmosfera positiva na equipe, a motivação dos jogadores suplentes, o recrutamento e seleção de atletas, e a falta de recursos financeiros. Por último, refira-se um recente estudo realizado por FREY (2007) com 10 treinadores americanos da National Collegiate Athletic Association (NCAA), no qual os fatores considerados mais estressantes incluíam a comunicação, controle e recrutamento dos atletas, assim como a pressão de lidar com distintos papéis e responsabilidades em simultâneo.

Para além da identificação das principais fontes de "stress", a determinação das estratégias de "coping" utilizadas pelos treinadores para lidar com essas fontes de "stress" tem também suscitado alguma atenção dos investigadores da área. Na investigação anteriormente referida desenvolvida com treinadores da NCAA, FREY (2007) procurou também identificar as estratégias de "coping" utilizadas pelos sujeitos para lidarem com situaçôes estressantes. Os resultados revelaram que estes recorriam a um vasto leque de estratégias cognitivas (e.g., focalização em aspectos que podiam controlar, manter a situação "em perspectiva"), de controle emocional (e.g., enfatizar o divertimento como parte da filosofia de treino, recorrer ao apoio social,), e comportamentais (e,g., ler, massagens, exercício), muitas vezes em simultâneo.

Todavia, embora pareça ser evidente que múltiplos aspectos se podem constituir como geradores de ansiedade, nos treinadores e que estes recorrem a diferentes estratégias de "coping" para lidar com os seus efeitos negativos, são certamente necessárias mais investigaçôes que clarifiquem a dinâmica da relação entre estas variáveis e o desempenho dos treinadores.

Por último, é também importante salientar a importância crescente da exploração do papel de outras emoções para além da ansiedade no desempenho, um domínio ainda muito pouco explorado na psicologia do desporto - mesmo em estudos centrados em atletas - e que tem suscitado, especialmente nos últimos anos, o interesse de diversos investigadores (e.g., Crocker \& Graham, 1995; Gould \& Udry, 1994; Hanin, 2000; Lazarus, 2000; Mellalieu, Hanton \& Jones, 2003). Com efeito, parece que a psicologia do desporto começa a despertar para a ideia de que a investigação centrada, isoladamente, na variável da ansiedade, é insuficiente para abranger as reações emocionais, começando a considerar-se "a complexidade da vida emocional em contextos desportivos" (CRUZ, 1996, p.204), por exemplo no que se refere ao papel e influência de outras emoções negativas e positivas (e.g., irritação/raiva, felicidade/ alegria, culpa, medo, vergonha) no desempenho desportivo. Neste contexto, uma análise mais aprofundada desta temática poderá promover uma melhor compreensão da influência de diferentes emoções no rendimento e comportamento desportivo dos atletas e outros agentes desportivos; para além disso, poderá contribuir para "lançar os alicerces" para o 
futuro desenvolvimento de instrumentos válidos para avaliar as emoções no desporto.

Por outro lado, no que concerne às metodologias de investigação, importa salientar a cada vez maior atenção que os métodos de investigação qualitativa têm vindo a receber por parte dos investigadores no domínio da psicologia do desporto nas últimas décadas (JACKSON, 1995; WeINBERG \& Gould, 2007). Em grande medida, tal estará relacionado com o fato de esta metodologia fornecer uma perspectiva mais detalhada e aprofundada das emoções e cognições das pessoas, comparativamente aos métodos quantitativos (Edwards, Kingston, Hardy \& Gould, 2002). O recurso a entrevistas, por exemplo, ao permitir que o sujeito descreva com as suas próprias palavras os eventos que ocorrem naturalmente e o modo como se relacionam com as variáveis em análise, proporciona uma profundidade e riqueza de informação adicional que não é conseguida com as medidas de auto-relato geralmente utilizadas em estudos quantitativos e facilita uma melhor compreensão dos seus estados psicológicos. Desta forma, esta abordagem pode ser especialmente útil na identificação de novas variáveis e relações em áreas não exploradas ou na obtenção de avaliações exaustivas das emoções e cognições dos sujeitos (Gould \& Krane, 1992). Neste contexto, diversos investigadores advertem para o excesso de confiança depositado na informação quantitativa e encorajam o recurso a abordagens qualitativas na investigação de fenômenos relacionados com o rendimento e excelência desportiva.

Decorrendo do exposto, o presente estudo, ao recorrer a uma metodologia qualitativa, designadamente a entrevista, pretendeu preencher algumas lacunas inerentes ao recurso a instrumentos de auto-relato (decorrentes de uma abordagem predominantemente quantitativa), procurando identificar, junto de treinadores de elite - uma população geralmente "esquecida" na investigação em psicologia do desporto -, as competências e características psicológicas mais importantes para o sucesso desportivo, as principais fontes de "stress" e ansiedade, as estratégias de "coping" mais utilizadas e, ainda, as principais emoções experienciadas.

\section{Metodologia}

\section{Sujeitos}

Participaram neste estudo seis treinadores de várias nacionalidades (portuguesa, brasileira e sueca), cinco do sexo masculino e um do sexo feminino, com idades compreendidas entre os 55 e os 63 anos (M $=59 \pm 3,03)$, envolvidos nas seguintes modalidades: voleibol $(\mathrm{N}=1)$, atletismo $(\mathrm{N}=1)$, futebol $(\mathrm{N}=2)$, basquetebol $(\mathrm{N}=1)$ e handebol $(\mathrm{N}=1)$. Atendendo aos objetivos deste estudo, apenas foram considerados treinadores que, durante a sua carreira desportiva, tivessem obtido marcas de relevo nas respectivas modalidades, designadamente classificaçôes entre o $1^{\circ} \mathrm{e}$ o $3^{\circ}$ lugar em Campeonatos da Europa ou Mundo. Adicionalmente, foram incluídos dois treinadores que, apesar de não terem conquistado títulos, taças ou campeonatos internacionais, possuíam um curriculum desportivo extenso e bem-sucedido (incluindo diversas vitórias em campeonatos e competiçôes nacionais), que os tornavam referências nas suas modalidades.

\section{Instrumentos e procedimentos}

Para a realização deste estudo, os dados foram recolhidos através da aplicação de uma entrevista

semi-estruturada e de resposta aberta, desenvolvida com base nos guias de entrevistas de TAYLOR e SCHNEIDER (1992), que abrangia aspectos relacionados com: 1) características/competências psicológicas mais importantes para o seu sucesso desportivo; 2) fontes de "stress" e ansiedade; 3) estratégias de "coping”; e 4) outras emoçôes (para além da ansiedade), com influência no rendimento.

Em todas as entrevistas foi assegurada a confidencialidade e anonimato dos dados e recebida autorização para gravação das mesmas. Importa salientar que as entrevistas se efetuaram em locais reservados, de forma a evitar influência de terceiros, tendo durado de 90 a 120 minutos. No decorrer da entrevista, a entrevistadora adotou uma postura não crítica e não avaliativa, intervindo apenas quando fosse estritamente necessário esclarecer alguma afirmação ou ponto de vista.

Finalmente, importa salientar que o presente estudo foi realizado no âmbito de um projeto de investigação aprovado pelo Conselho Científico do Instituto de Educação e Psicologia da Universidade do Minho (Portugal) e por um Painel de Avaliação da Fundação para a Ciência e Tecnologia (Ministério da Ciência, Tecnologia e Ensino Superior, Portugal). 


\section{Análise dos dados}

A análise de conteúdo foi efetuada de acordo com os procedimentos sugeridos por especialistas em metodologia da investigação qualitativa e da análise de conteúdo dos mais variados contextos, incluindo o desportivo (Dugdale, EkLund \& GORDON, 2002; GOULD, EKLUND \& JACKSON, 1992; Gould, Jackson \& Finch, 1993; Scanlan, Stein \& RavizZA, 1991). Esta análise qualitativa obedeceu ainda a alguns princípios fundamentais, sendo realizada em quatro etapas sucessivas: 1) transcrição das entrevistas na sua totalidade; 2 ) leitura e análise cuidada (incluindo segunda e terceira leituras) das situações descritas, por parte de um painel de cinco psicólogos do desporto, familiarizados com este tipo de análise metodológica; 3) identificação e descrição ("em bruto") de temas específicos descritos pelos treinadores; e 4) análise indutiva dos temas identificados pelo painel de juízes, posteriormente agrupados em dimensões mais globais. De recordar que a análise indutiva permite que temas e dimensões gerais possam ser criados "a posteriori”, a partir da interpretação lógico-semântica do texto (EDWARDS et al., 2002).

Na primeira etapa, a transcrição das entrevistas foi efetuada de forma a reproduzir fielmente o discurso dos treinadores, no sentido de tratar e organizar as entrevistas, que se encontravam em estado bruto, para uma forma coerente e lógica.

$\mathrm{Na}$ segunda fase, as entrevistas foram sujeitas a uma leitura prévia que tinha por objetivo dar uma ideia global do que foi respondido, sendo, de seguida, realizadas segunda e terceira leituras atentas e cuidadas, que visaram identificar significados e procurar uma coerência que permitisse elaborar o raciocínio e organizar as informaçôes fornecidas pelos participantes. Com base nestas leituras, foi possível realizar uma interpretação lógico-semântica do conteúdo das respostas, que permitiu identificar e/ou descrever temas específicos que representavam situações ou resumos das principais ideias referidas nas respostas.

Num último momento, fez-se o agrupamento dos temas específicos com significados idênticos em dimensões gerais; em algumas questôes os sujeitos referiram mais do que uma dimensão geral. Como critério de inclusão de uma resposta numa dimensão, foi definida a obrigatoriedade de todos os investigadores assim o terem considerado. Nos casos em que tal não se verificou, a seleção da dimensão na qual a resposta foi incluída foi efetuada a partir de reflexão conjunta, sendo as transcrições relidas até se chegar a um consenso; o ponto de vista da entrevistadora foi considerado especialmente relevante nas discussões interpretativas, na medida em que possuía a vantagem de ter conversado diretamente com os participantes do estudo.

Por último, importará referir que a discussão dos resultados, que a seguir se apresenta, foi realizada com base nas dimensões gerais definidas para cada uma das quatro questôes colocadas aos atletas, com o objetivo de fazer evidenciar as conclusões mais significativas.

\section{Resultados}

\section{As características e/ou competências psicológicas mais importantes para o sucesso desportivo}

A análise qualitativa das competências e/ou características psicológicas que os treinadores consideravam mais importantes para o seu sucesso, apresentada na TABELA 1 , permitiu identificar sete dimensōes gerais: 1) autoconfiança; 2) autocontrole emocional; 3) capacidade de motivar e formular objetivos para os atletas; 4) concentração; 5) liderança; 6) motivação; e 7) prazer. 
TABELA 1 - Dimensões gerais e temas específicos das características/competências psicológicas mais importantes para o sucesso desportivo dos treinadores e frequência de treinadores que as referem.

\begin{tabular}{|c|c|c|c|}
\hline \multicolumn{2}{|c|}{$\begin{array}{l}\text { Treinadores que } \\
\text { referem a dimensão }\end{array}$} & \multirow{2}{*}{ Dimensão geral } & \multirow{2}{*}{ Temas específicos } \\
\hline $\mathbf{N}$ & $\%$ & & \\
\hline \multirow{2}{*}{3} & \multirow{2}{*}{50} & \multirow{2}{*}{ Motivação } & motivação \\
\hline & & & capacidades volitivas \\
\hline \multirow{2}{*}{2} & \multirow{2}{*}{33,3} & \multirow{2}{*}{ Autoconfiança } & ter confiança e acreditar nas suas capacidades pessoais \\
\hline & & & pensamento positivo \\
\hline \multirow{2}{*}{2} & \multirow{2}{*}{33,3} & \multirow{2}{*}{ Concentração } & concentração no jogo e nos atletas \\
\hline & & & "fechar-se", direcionar-se para o jogo \\
\hline 2 & 33,3 & Liderança & capacidade de liderança \\
\hline 2 & 33,3 & Prazer & gostar do que faz \\
\hline 1 & 16,7 & $\begin{array}{l}\text { Motivação e formulação de objetivos para } \\
\text { os atletas }\end{array}$ & saber motivar e formular objetivos para os atletas \\
\hline 1 & 16,7 & Autocontrole emocional & manter a calma e a serenidade \\
\hline
\end{tabular}

A 'motivação' foi a competência psicológica referida por um maior número de treinadores. ...eu penso que um conjunto de factores relacionados com as capacidades volitivas (...) são muito importantes (Treinador 2).

... a motivação. As pessoas podem pensar " $\mathrm{O}$ treinador, desde que se lhe pague ao fim do mês, e tal, gere as coisas e pronto..."; eu penso que não, eu penso que a motivação é fundamental, porque, se uma pessoa não está motivada não consegue transmitir essa mesma motivação aos atletas e eu penso que será, sem dúvida, aquilo que é fundamental no treinador. Gostar daquilo que faz e sentir-se motivado... (Treinador 5).

Adicionalmente, dois dos treinadores mencionaram também a 'autoconfiança', a 'concentração', a 'liderança' e o 'prazer', existindo ainda duas competências/características psicológicas que foram especificadas por apenas um treinador: a capacidade de saber 'motivar e formular objetivos para os atletas' e de manter o 'autocontrole emocional'.

...é óbvio que também é muito importante, saber estabelecer os objectivos dos atletas ou da equipa, porque eu vejo colegas meus que estabelecem objectivos, para os atletas, que são irrealistas, quer dizer: "Tu vais conseguir fazer mínimos para um Campeonato do Mundo", quando sabe, à partida, que ele não consegue fazer isso, que o atleta não tem qualidades para, e tentam motivar o atleta, mas eu penso que isso não motiva o atleta, antes pelo contrário; quer dizer o atleta faz uma, faz duas, faz vinte, faz trinta provas e não consegue fazer isso, (...) e eu penso que o saber criar os objectivos, objectivos que sejam desafiantes, como é óbvio, mas que sejam reais, penso que, subir degrau a degrau, quer dizer, penso que isso é fundamental (Treinador 5).

...um certo equilíbrio na forma como aborda os jogos, na forma como aborda as situaçōes de jogo com os atletas, no próprio diálogo durante o jogo com os atletas, é muito importante não deixar transparecer aquilo que nos "vai na alma" e às vezes não é fácil, porque as situações descambam para situações incontroláveis pelo próprio treinador (...) o treinador não pode...tem que manter uma serenidade e uma confiança, pronto, que não vacile, ainda que, todos nós sabemos, nós somos humanos e temos momentos que, e eu não consigo, em muitas situaçôes não consegui controlar, noutras consigo controlar muito bem... Por exemplo, no meu caso pessoal, creio que controlo muito melhor os jogos muito difíceis do que os jogos muito fáceis, nos jogos mais fáceis eu "dou barraca" e pronto, cometo erros e às vezes faço até intervenções que penso que não deveriam ser feitas; nos jogos que em que são jogos mais difíceis, talvez por causa de uma preparação mental maior, eu consigo ter algum sangue frio, alguma serenidade, consigo transparecer muito mais serenidade... (Treinador 2).

\section{As principais fontes de "stress" e ansiedade}

$\mathrm{Na}$ TABELA 2, são apresentadas as fontes de "stress" experienciadas pelos treinadores, agrupadas em cinco dimensões gerais: 1) não ter o desempenho esperado; 2) natureza da competição; 3) percepção de falta de prontidão física, técnica e/ ou tática; 4) pressões externas; e 5) sofrimento dos atletas. 
DIAS, C.; CRUZ, J.F. \& FONSECA, A.M.

TABELA 2 - Dimensões gerais e temas específicos das situações ou acontecimentos geradores de elevados níveis de "stress", pressão ou ansiedade e frequência de treinadores que as referem.

\begin{tabular}{|c|c|c|c|}
\hline \multicolumn{2}{|c|}{$\begin{array}{l}\text { Treinadores que } \\
\text { referem a dimensão }\end{array}$} & \multirow[t]{2}{*}{ Dimensão geral } & \multirow[t]{2}{*}{ Temas específicos } \\
\hline $\mathbf{N}$ & $\%$ & & \\
\hline \multirow{2}{*}{3} & \multirow{2}{*}{50} & \multirow{2}{*}{ Não ter o desempenho esperado } & não atingir objetivos desportivos \\
\hline & & & perder / não ganhar \\
\hline 1 & 16,7 & Natureza da competição & importância do jogo \\
\hline 1 & 16,7 & $\begin{array}{l}\text { Percepção de falta de prontidão física, } \\
\text { técnica e/ou tática }\end{array}$ & preparação dos jogos \\
\hline 1 & 16,7 & Sofrimento dos atletas & sofrimento dos atletas por não atingirem os objetivos \\
\hline 1 & 16,7 & Pressões externas & pressão dos dirigentes \\
\hline
\end{tabular}

A dimensão mais apontada foi 'não ter o desempenho esperado', que compreendia aspectos relacionados com a não obtenção dos objetivos previamente definidos, e com preocupações em perder ou não ganhar.

...saber se a atleta vai conseguir o objectivo que nós propusemos ou não, é a incerteza do resultado, porque tudo pode acontecer, sobretudo isso. Mesmo quando a atleta está muito bem, a experiência dizme que muitas vezes os atletas estão muito bem, no melhor da sua forma, e há qualquer coisa que não funciona e o resultado não aparece (Treinador 4).

Todas as outras dimensões (i.e., 'natureza da competição', 'percepção de falta de prontidão física, técnica e/ou tática', 'sofrimento dos atletas' e 'pressões externas') foram referidas apenas por um treinador.

\section{As estratégias de "coping" com o "stress" e a ansiedade}

No que respeita às estratégias de "coping" utilizadas pelos treinadores para lidarem com situações estressantes e/ou problemáticas, foram identificadas nove dimensões gerais: 1) aceitação das situações; 2) apoio emocional; 3) autocontrole emocional/ redução da tensão; 4) autodistração; 5) "coping" ativo; 6) humor; 7) isolamento; 8) reavaliação positiva das situações; e 9) ventilação de emoções (TABELA 3).

As dimensões mencionadas por um maior número de treinadores foram claramente o 'autocontrole emocional/redução da tensão' e a 'reavaliação positiva' das situaçôes.

TABELA 3 - Dimensões gerais e temas específicos das estratégias de "coping" para lidar com situações geradoras de "stress", ansiedade ou pressão e frequência de treinadores que as referem.

\begin{tabular}{|c|c|c|c|}
\hline \multicolumn{2}{|c|}{$\begin{array}{l}\text { Treinadores que } \\
\text { referem a dimensão }\end{array}$} & \multirow{2}{*}{ Dimensão geral } & \multirow{2}{*}{ Temas específicos } \\
\hline $\mathbf{N}$ & $\%$ & & \\
\hline \multirow[t]{2}{*}{5} & \multirow[t]{2}{*}{83,3} & \multirow[t]{2}{*}{$\begin{array}{l}\text { Autocontrole emocional/ } \\
\text { redução de tensão }\end{array}$} & $\begin{array}{l}\text { manter a calma e/ou a serenidade } \\
\text { respiração e relaxamento }\end{array}$ \\
\hline & & & autoverbalizaçôes e pensamentos positivos \\
\hline \multirow[t]{2}{*}{5} & \multirow[t]{2}{*}{83,3} & \multirow[t]{2}{*}{ Reavaliação positiva da situação } & procurar ver a situação de uma perspectiva positiva \\
\hline & & & recordação de experiências anteriores (experiência) \\
\hline \multirow{2}{*}{3} & \multirow{2}{*}{50} & \multirow{2}{*}{ "Coping" ativo } & esforço e trabalho \\
\hline & & & tentativa ativa de resolução do problema/situação \\
\hline \multirow{2}{*}{2} & \multirow{2}{*}{33,3} & \multirow{2}{*}{ Autodistração } & pensar e falar noutras coisas \\
\hline & & & envolver-se noutras atividades (e.g., passear, praticar um desporto) \\
\hline 2 & 33,3 & Isolamento & isolamento ('dar uma volta' sozinho) \\
\hline 1 & 16,7 & Aceitação & aceitar que as coisas acontecem \\
\hline 1 & 16,7 & Apoio emocional & receber apoio emocional da equipe técnica \\
\hline 1 & 16,7 & Humor & brincar com a situação \\
\hline 1 & 16,7 & Ventilação de emoções & expressar, "deitar" para fora as emoções \\
\hline
\end{tabular}


Os treinadores participantes no presente estudo recorriam a estratégias de 'autocontrole emocional/ redução da tensão' com o objetivo de diminuir os seus níveis de ansiedade e, simultaneamente, não transmitir essa ansiedade aos atletas.

...o que é preciso (...) é demonstrar o mais possível sereno, pronto para dar serenidade, confiança à equipa neste momento e estar o mais sereno possível para poder dar resposta àquilo que é a função do treinador: orientar um jogo com qualidade, com distanciamento, num jogo completamente decisivo, sabermos que é um jogo decisivo mas distanciarmo-nos da pressão, dos aspectos da ansiedade, etc., e, de facto, ser menos ansioso e ser mais, inteligente, digamos, ser mais cerebral do que emocional (Treinador 2).

...tentar mentalizar-me que tenho que dar o melhor de mim sem me exceder, sem extravasar sentimentos de revolta ou de grande ansiedade, é no fundo isso... (Treinador 3).

Eu por acaso, segundo dizem, sou muito boa a dissimular, a minha ansiedade, segundo dizem as pessoas, mesmo quando (...) ganhava medalhas, eu ficava contente como toda a gente, mas diziam-me que eu era um bocado fria a encarar os resultados. As pessoas estavam totalmente enganadas, conseguia dissimular bem e as pessoas, pronto, viam que eu ficava contente, mas não era aquela alegria expansiva... Mas sinto muita ansiedade antes das provas, por incrível que pareça, depois destes anos todos, continuo a sentir demasiada ansiedade, talvez agora a saiba controlar melhor, mas, eu penso que é uma coisa que nós podemos aprender a controlar, mas que não deixamos nunca de sentir. Quando uma pessoa está motivada e tem um objectivo determinado, porque, pronto, o objectivo, eu considero que o objectivo não é do atleta, o objectivo é do atleta e do treinador, estamos empenhados em determinada situação, sem dúvida que sinto muita ansiedade. Consigo controlá-la melhor, tento não a transmitir aos atletas, penso que tenho conseguido, a não ser aquelas atletas que treinam comigo durante muitos anos, e que sabem e conhecem-me bem (Treinador 5).

...tu procuras acreditar, tu procuras estar realmente muito mais tranquilo, passar as melhores informações... (Treinador 1).

No que respeita à 'reavaliação', os treinadores procuravam analisar as situaçôes problemáticas de uma perspectiva positiva, socorrendo-se, na maior parte dos casos, de situações passadas resolvidas de forma satisfatória.

....se nós aqui no nosso computador começamos a ter essas gavetas com essas experiências todas, quando abrimos a gaveta, olha já vivi este momento, voltamos a viver este momento, vamos encará-lo de uma maneira... e então preparamo-nos... (Treinador 2).

...tentar mentalizar-me que, realmente, fiz tudo durante a semana para que o jogo corra bem... (Treinador 3).

Tento convencer-me que fiz tudo bem feito e que as coisas vão correr bem, mas isso nem sempre é fácil. Começo a ver, sobretudo, situações passadas, a vivenciar situaçōes passadas que resultaram: "Estava cheia de medo nesta altura, no ano passado e há dois anos e as coisas correram tão bem, porque é que agora não vão correr bem?!"; começo a fazer comparações com momentos de êxito, sobretudo isso. E tentar mudar pensamentos... (Treinador 5).

\section{As emoções}

No que respeita às emoções que influenciavam o desempenho dos treinadores entrevistados, foram identificadas três dimensões gerais: 1) felicidadealegria/bem-estar; 2) irritação/raiva; e 3) medo (TABELA 4).

Destas, a 'felicidade-alegria/bem-estar' e a 'irritação/raiva' foram apontadas por dois treinadores, enquanto o 'medo' apenas foi citado por um; houve ainda um treinador que não identificou nenhuma emoção que influenciasse o seu desempenho. 
DIAS, C.; CRUZ, J.F. \& FONSECA, A.M.

TABELA 4 -Dimensões gerais e temas específicos das emoções e frequência de treinadores que as referem.

* Embora seja relativamente frequente surgir a referência ao medo na avaliação da ansiedade, no presente estudo, a questão formulada referia-se concretamente 'a outras emoções para além da ansiedade' percebidas pelos treinadores como podendo afetar o seu desempenho; daí que, neste caso, se tenha optado por considerar o medo como uma emoção distinta da ansiedade.

\begin{tabular}{|c|c|c|c|}
\hline \multicolumn{2}{|c|}{$\begin{array}{l}\text { Treinadores que } \\
\text { referem a dimensão }\end{array}$} & \multirow[t]{2}{*}{ Dimensão geral } & \multirow[t]{2}{*}{ Temas específicos } \\
\hline $\mathbf{N}$ & $\%$ & & \\
\hline 2 & 33,3 & Felicidade-alegria/bem-estar & $\begin{array}{c}\text { contentamento } \\
\text { alegria }\end{array}$ \\
\hline 2 & 33,3 & Irritação/raiva & raiva \\
\hline 1 & 16,7 & Medo & medo \\
\hline
\end{tabular}

Os treinadores consideraram a 'irritação/raiva' e o 'medo' negativos e a 'felicidade-alegria/bem-estar' positiva.

Raiva, não funciona muito comigo... (Treinador 5).

Agora, posso dizer que medo, tenho muito e é mau porque sou uma pessoa, embora eu tente esconder, camuflar essa situaçãa, se por vezes eu não conseguir e o atleta se aperceber, é "meio caminho andado" para que o atleta comece também a questionar e a colocar em causa determinadas coisas e comece também a estar nervoso, a estar com medo, é porque as coisas não estão assim tão bem; portanto, o medo é uma coisa que eu sinto mas que não gostava de sentir e que eu tento tudo para que os atletas não se apercebam disso (Treinador 5).

A alegria. Eu penso que uma pessoa que seja alegre, normalmente, se está bem preparada e se é alegre, se vai para a competição com alegria, eu penso que é muito positivo (Treinador 1).

\section{Discussão}

A presente investigação pretendia, recorrendo a entrevistas aprofundadas com treinadores de elite, identificar as competências/características psicológicas mais importantes para o seu sucesso desportivo, as principais fontes de "stress" experienciadas e as estratégias de "coping" utilizadas em situaçôes estressantes e/ou problemáticas, bem como explorar o papel de outras emoções, para além da ansiedade, no desempenho dos treinadores.

Adicionalmente, como foi anteriormente referido, a metodologia escolhida justifica-se pela necessidade de se aprofundarem os estudos de natureza quantitativa e, porque, nos últimos anos, tem sido uma abordagem cada vez mais aconselhada por alguns investigadores de renome no domínio da psicologia do desporto (e.g., Edwards et al., 2002; Gould, EKLund \& JACKSON, 1993; Gould, FinCH \& JACKSON, 1993). Importa porém salientar que não obstante permitirem o acesso a informação dificilmente conseguida de outra forma, as investigaçôes qualitativas e, especificamente, a comparação dos resultados com outras investigações de cariz qualitativo, tem limitaçôes. Com efeito, já diversos investigadores alertaram que as comparações entre estudos qualitativos, apesar de necessárias e desejáveis, devem ser realizadas com algum cuidado, pois diferenças no paradigma da investigação qualitativa ao nível das entrevistas, observações, natureza e limites da amostra e abordagens metodológicas podem, em alguns casos, aumentar a probabilidade de gerar respostas e categorias distintas (GOULD, FINCH \& JACKSON, 1993; James \& Collins, 1997). Por outro lado, como afirmaram Krane, ANDERSEN e Strean (1997, p.217), "esperar similaridade entre os investigadores qualitativos seria uma 'codificação prematura' da 'forma correta de fazer trabalho qualitativo' ". Todos estes aspectos sugerem assim um cuidado e alerta especiais na comparação dos resultados efetuada.

Ainda assim, e no que concerne às características e/ ou competências psicológicas mais importantes para o sucesso desportivo saliente-se o fato de os treinadores se preocuparem em formular objetivos para os seus atletas. Estes resultados são consistentes com investigaçôes anteriores, que revelaram que a formulação de objetivos individuais e coletivos constituía uma estratégia extensivamente utilizada pelos treinadores em diferentes contextos (e.g., desporto universitário, desporto federado) para melhorarem o desempenho e sucesso das suas equipes e atletas (WEINBERG, BURKE \& Jackson, 1997; Weinberg, Butt \& Knight, 2001; Weinberg, Butt, Knight \& Perritt, 2001). 
De forma similar, os resultados relativos ao autocontrole emocional, vão ao encontro da anteriormente referida investigação de Gould et al. (2002), na medida em que esta competência também foi referida pelos treinadores olímpicos participantes naquela investigação; contudo, para além deste, nenhum outro aspecto foi também mencionado pelos treinadores participantes no presente estudo. Tal fato não será de todo surpreendente se considerarmos que, na investigação de Gould et al. (2002), os treinadores foram inquiridos relativamente às competências, características ou fatores psicológicos mais importantes para o sucesso nos Jogos Olímpicos, uma competição muito específica e com características muito definidas. Em contraste, na presente investigação os treinadores foram questionados relativamente às características/ competências que consideravam mais relevantes para o sucesso desportivo numa perspectiva mais global, de vida e de carreira.

Por último, importará realçar que o fato de metade dos treinadores ter destacado a importância da manutenção de níveis de motivação elevados ao longo da sua carreira demonstra a sua importância numa "profissão" muitas vezes imprevisível, por vezes mal compreendida, e onde algumas vezes os treinadores servem de "bode expiatório" para os maus resultados e/ou o rendimento dos atletas ou equipes.

Por outro lado, as fontes de "stress" identificadas parecem ir ao encontro à anteriormente referida investigação de Sullivan e Nashman (1993) com treinadores olímpicos, na qual estes referiram ter percebido como estressantes, entre outros, aspectos relacionados com pressōes das mídias, tempo de preparação insuficiente, ou a representação do país. Adicionalmente, os treinadores entrevistados por FreY (2007) também referiram a pressão de lidar com distintos papéis e responsabilidades em simultâneo. Já a seleção e/ou recrutamento e comunicação com os atletas, que se pareciam constituir como fontes comuns de "stress" em distintas investigações com treinadores (e.g., Frey, 2007; Sullivan \& NASHMAN, 1993; WANG \& RAMSEY, 1998), não foram referidas no nosso estudo. O contrário ocorreu no que respeita à preocupação em não ter o desempenho esperado, a dimensão assinalada por mais treinadores na presente investigação mas que não emergiu nos estudos citados anteriormente. Esta dissemelhança poderá estar relacionada com o fato de essas investigaçōes se centrarem sobre a experiência de "stress" em situações muito específicas (e.g., Jogos Olímpicos), enquanto na presente pesquisa procuramos identificar as principais fontes de "stress" numa perspectiva mais global. Logo, a relevância dada ao seu desempenho poderá explicar-se por este estar muitas vezes diretamente ligado ao seu sucesso desportivo, e, logo, profissional e financeiro.

Quanto às estratégias de "coping" identificadas na presente investigação são congruentes com a investigação de FrEY (2007), na qual os treinadores especificaram estratégias relacionadas com o autocontrole emocional e a reavaliação positiva das situações, mas também comportamentos de "coping" ativo, autodistração, ou apoio emocional. Além disso, à semelhança do que ocorreu no nosso estudo, também no estudo de FREY os treinadores revelaram recorrer em simultâneo a diversas estratégias de "coping", indo de encontro à ideia de que “...o 'coping' é um processo dinâmico e complexo” (GOULD, EKLUND \& JACKSON, 1993, p.86-7). Adicionalmente, saliente-se que, apesar de ter sido encorajador notar que a maioria das estratégias de "coping" utilizadas pelos treinadores de elite era adaptativa (e.g., 'reavaliação positiva'), os comportamentos de "coping" desadaptativos identificados (e.g., 'isolamento') sugerem que devem ser efetuados esforços para educar e fornecer apoio psicológico a treinadores que recorrem a comportamentos de "coping" menos eficazes e potencialmente desajustados ou inadequados.

Finalmente, no que concerne às emoções, importa realçar nestes dados, é que os treinadores experienciavam outros estados emocionais para além da ansiedade. Adicionalmente, estes resultados também sugerem que embora o valor adaptativo de algumas emoçōes seja claro e inequívoco (a felicidade/alegria era avaliada como positiva e o medo como negativo, por exemplo), outras emoções podem ter um papel mais ambíguo. Mais especificamente, a emoção de irritação/raiva - geralmente considerada negativa pela literatura da especialidade (e.g., Hanin, 2000) -, parecia nem sempre ser experienciada dessa forma pelos treinadores, sugerindo que acontece com emoção o mesmo que com a ansiedade, por vezes considerada positiva e outras vezes negativa. 


\section{Conclusões e implicações}

No que respeita às características/competências que os treinadores consideravam importantes para o seu sucesso desportivo, embora a motivação tenha sido a competência mais consensualmente referida podendo constituir-se como um indicador relevante para futuras intervenções junto desta população - é importante não desconsiderar as outras dimensões psicológicas aludidas (e.g., autoconfiança, liderança, capacidade de motivar e formular objetivos para os atletas). Por outras palavras, estes resultados enfatizam a importância de fornecer o apoio psicológico geralmente direcionado para os atletas à população de treinadores. Todavia, para que esse apoio seja o mais eficaz e individualizado possível, é urgente a realização de mais investigação nesta área, no sentido se esclarecer se as características/competências psicológicas mais importantes para o sucesso são função, por exemplo, do tipo de competição (e.g., Jogos Olímpicos, Campeonatos Nacionais), características individuais dos treinadores (e.g., sexo, idade, experiência), ou fatores socioculturais (e.g., contexto desportivo envolvente).

Por outro lado, as fontes de "stress" e ansiedade experienciadas pelos sujeitos deste estudo, assim como as estratégias de "coping" utilizadas em situações estressantes e/ ou problemáticas eram, de uma forma geral, consistentes com investigações anteriores neste domínio e nesta população.

No entanto, o fato de também terem sido apontados como estressantes aspectos que, de uma forma geral, não são contemplados na generalidade dos instrumentos de avaliação quantitativa, designadamente aqueles desenvolvidos para atletas (e.g., o sofrimento dos atletas), confirma a mais-valia de investigaçôes de cariz qualitativo, as quais poderão permitir aceder a informações específicas e contextualizadas, em função da população e do contexto. Adicionalmente, uma vez que os sujeitos pareciam recorrer conjuntamente a distintas estratégias para lidarem com as situações estressantes e problemáticas, que encontravam, consideramos que também seria interessante a realização de estudos longitudinais que possibilitem o estabelecimento de uma relação entre as fontes de "stress" e as estratégias de "coping" utilizadas para lidar com as mesmas. Este gênero de "design" permitiria também a monitorização de uma possível natureza dinâmica das respostas de "coping" ao longo da época e a análise da eficácia de intervenções a este nível.

Com efeito, vários autores sugeriram já que os atletas podem usar diferentes estratégias de "coping" em diferentes fases do ciclo competitivo e de acordo com as exigências de situações específicas, recomendando o desenvolvimento de estudos qualitativos e longitudinais em que tenham lugar múltiplas entrevistas ao longo da época ou em múltiplas épocas e em diferentes contextos de rendimento (e.g., competiçōes fáceis/difíceis; lesões) (e.g., Gould, EKLUND \& JACKson, 1993; Gould, Finch \& Jackson, 1993; Holt \& HogG, 2002). Na nossa opinião, este raciocínio poderá e deverá ser alargado aos treinadores. Desta forma, as ligações entre o uso de estratégias de "coping", redução ou gestão do "stress" e o rendimento podiam ser mais clarificadas. Além disso, a realização deste gênero de estudos qualitativos e longitudinais também poderá ajudar os investigadores a ultrapassarem as limitações de entrevistas retrospectivas isoladas, nomeadamente no que respeita à precisão dos resultados recordados, ou à influência dos resultados das competições na recordação das percepções de eficácia das estratégias utilizadas.

$\mathrm{Na}$ mesma linha, considerando que o valor e utilidade de algumas emoções referidas pelos treinadores pareciam assumir um papel ambíguo, no sentido em que variavam em função da situação el ou do indivíduo (e.g., irritação/raiva), importará tentar relacionar as emoçôes experienciadas pelos treinadores com as estratégias de "coping" específicas (eficácia, automaticidade) utilizadas na sua gestão.

De fato, o presente estudo permitiu evidenciar o importante papel que outras emoções, para além da ansiedade, parecem assumir na competição desportiva, reforçando assim a necessidade de uma abordagem mais ampla e integradora neste domínio de investigação. Se o que se pretende é promover o sucesso desportivo, é essencial compreender melhor o papel de diferentes estados emocionais no desempenho - um domínio sobre o qual, como foi anteriormente referido, o conhecimento é ainda escasso -, e, posteriormente, desenvolver programas de auto-regulação emocional que incluam não só a ansiedade, mas também outras emoções. Além disso, porque surgem e atuam num contexto que por si só é altamente complexo e multifacetado, a compreensão do valor adaptativo das emoções no contexto desportivo poderá ser melhorada se reconhecermos que integram um sistema de múltiplas variáveis interdependentes (e.g., variáveis pessoais e contextuais), devendo por isso ser consideradas, desejavelmente, de forma combinada e/ou em simultâneo. 


\section{Abstract}

Emotions, stress, anxiety and coping: a qualitative study with international level coaches

The influence of psychological factors on athletes' sport performance is, in general, well documented; however, there is little understanding of the role these factors and processes play in coaches. In this sense, using a semi-structured interview, the present study aimed to identify, in six elite coaches aged between 55 and $63(M=59 \pm 3.03)$ and representing diverse sports, the most important psychological skills and characteristics for obtaining success, the major sources of stress and anxiety and the coping strategies most used in problematic and stressful situations; additionally, the role of further emotions, other than anxiety, in competitive performance, was also explored. The results revealed that: 1) motivation was considered one of the most important psychological skills/ characteristics for success in sport; 2) the major sources of stress were related with athletes' performance; 3 ) the coaches used several coping strategies simultaneously, usually adaptative; 4 ) in addition to anxiety, other positive and negative emotions influenced coaches' performance.

UnIterms: Stress; Anxiety; Coping; Emotions; Coaches; Qualitative investigation.

\section{Nota}

1. Esta investigação foi realizada com o apoio da Fundação para a Ciência e a Tecnologia (Ministério da Ciência, Tecnologia e Ensino Superior, Portugal), através da bolsa PRAXIS XXI/BD/20022/99.

\section{Referências}

CRUZ, J.F. Stress, ansiedade e rendimento na competição desportiva. Braga: Centro de Estudos em Educação e Psicologia/Instituto de Educação e Psicologia/Universidade do Minho, 1996.

CROCKER, P.R.; GRAHAM, T.R. Coping by competitive athletes with performance stress: gender differences and relationships with affect. The Sport Psychologist, Champaign, v.9, p.325-38, 1995.

DUGDALE, J.R.; EKLUND, R.C.; GORDON, S. Expected and unexpected stressors in major international competition: appraisal, coping, and performance. The Sport Psychologist, Champaign, v.16, p.20-33, 2002.

EDWARDS, T.; KINGSTON, K.; HARDY, L.; GOULD, D. A qualitative analysis of catastrophic performances and the associated thoughts, feelings and emotions. The Sport Psychologist, Champaign, v.16, p.1-19, 2002.

FREY, M. College coaches' experiences with stress: "Problem solvers" have problems, too. The Sport Psychologist, Champaign, v.21, p.38-57, 2007.

GIGES, B.; PETITPAS, A.J.; VERNACCHIA, R.A. Helping coaches meet their own needs: challenges for the sport psychology consultant. The Sport Psychologist, Champaign, v.18, p.430-44, 2004.

GOULD, D.; EKLUND, R.C.; JACKSON, S.A. 1988 U.S. Olympic wrestling excellence: mental preparation, precompetitive cognition, and affect. The Sport Psychologist, Champaign, v.6, p.358-82, 1992.

. Coping strategies used by U.S. Olympic wrestlers. Research Quarterly for Exercise and Sport, Washington, v.64, p.83-93, 1993.

GOULD, D.; FINCH, L.M.; JACKSON, S.A. Coping strategies used by national champion figure skaters. Research Quarterly for Exercise and Sport, Washington, v.64, p.453-68, 1993.

GOULD, D.; GUINAN, D.; GREENLEAF, C.; CHUNG, Y. A survey of U.S. Olympic coaches: variables perceived to have influenced athlete performances and coach effectiveness. The Sport Psychologist, Champaign, v. 16, p.229-50, 2002. GOULD, D.; HODGE, K.; PETERSON, K.; PETLICHKOFF, L. Psychological foundations of coaching: similarities and differences among intercollegiate wrestling coaches. The Sport Psychologist, Champaign, v.1, p.293-308, 1987. GOULD, D.; JACKSON, S.A.; FINCH, L.M. Sources of stress in national champion figure skaters. The Sport Psychologist, Champaign, v.7, p.354-74, 1993. 
DIAS, C.; CRUZ, J.F. \& FONSECA, A.M.

GOULD, D.; KRANE, V. The arousal-athletic performance relationship: current status and future directions. In: HORN, T.S. (Ed.). Advances in sport psychology. Champaign: Human Kinetics, 1992. p.119-41.

GOULD, D.; UDRY, E. The psychology of knee injuries and injury rehabilitation. In: GRIFFIN, L.Y. (Ed.). Rehabilitation of the injured knee. St. Louis: Mosby, 1994. p.86-98.

HANIN, Y.L. Successful and poor performance and emotions. In: HANIN, Y.L. (Ed.). Emotions in sport. Champaign: Human Kinetics, 2000. p.157-87.

HOLT, N.L.; HOGG, J.M. Perceptions of stress and coping during preparation for the 1999 women's soccer world cup finals. The Sport Psychologist, Champaign, v.16, p.251-71, 2002.

JACKSON, S. The growth of qualitative research in psychology. In: MORRIS, T.W.; SUMMERS, J. (Eds.). Sport psychology: theory, applications and issues. Milton: Jacaranda Wiley, 1995. p.575-91.

JAMES, B.; COLLINS, D. Self-presentational sources of competitive stress during performance. Journal of Sport and Exercise Psychology, Champaign, v.19, p.17-35, 1997.

KRANE, V.; ANDERSEN, M.B.; STREAN, W.B. Issues of qualitative research methods and presentation. Journal of Sport and Exercise Psychology, Champaign, v.19, p.213-18, 1997.

LAZARUS, R.S. How emotions influence performance in competitive sports. The Sport Psychologist, Champaign, v.14, p.229-52, 2000.

MELLALIEU, S.D.; HANTON, S.; JONES, G. Emotional labeling and competitive anxiety in preparation and competition. The Sport Psychologist, Champaign, v.17, p.157-74, 2003.

SCANLAN, T.K.; STEIN, G.L.; RAVIZZA, K. An in-depth study of former elite figure skaters: sources of stress. Journal of Sport and Exercise Psychology, Champaign, v.13, p.103-20, 1991.

SULLIVAN, P.A.; NASHMAN, H.W. The 1992 United States Olympic Team sport coaches: satisfactions and concerns. Applied Research in Coaching and Athletics Annual, Boston, v.8, p.1-14, 1993.

THELWELL, R.C.; WESTON, N.J.V.; GREENLEES, I.A.HUTCHINGS, N. A qualitative exploration of psychological skills use in coaches. The Sport Psychologist, Champaign, v.22, p.38-53, 2008.

WANG, J.; RAMSEY, J. The relationship of school type, coaching experience, gender and age to new coaches' challenges and barriers at the collegiate level. Applied Research in Coaching and Athletics Annual, Boston, v.13, p.1-22, 1998.

WEINBERG, R.; GOULD, D. Foundations of sport and exercise psychology. 4th. ed. Champaign: Human Kinetics, 2007. WEINBERG, R.S.; BURKE, K.L.; JACKSON, A.W. Coaches' and players' perceptions of goal setting in junior tennis: an exploratory investigation. The Sport Psychologist, Champaign, v.11, p.426-39, 1997.

WEINBERG, R.S.; BUTT, J.; KNIGHT, B. High school coaches' perceptions of the process of goal setting. The Sport Psychologist, Champaign, v.15, p.20-47, 2001.

WEINBERG, R.S.; BUTT, J.; KNIGHT, B.; PERRITT, N. Collegiate coaches' perceptions of their goal-setting practices: a qualitative investigation. Journal of Applied Sport Psychology, Philadelphia, v.13, p.374-98, 2001.

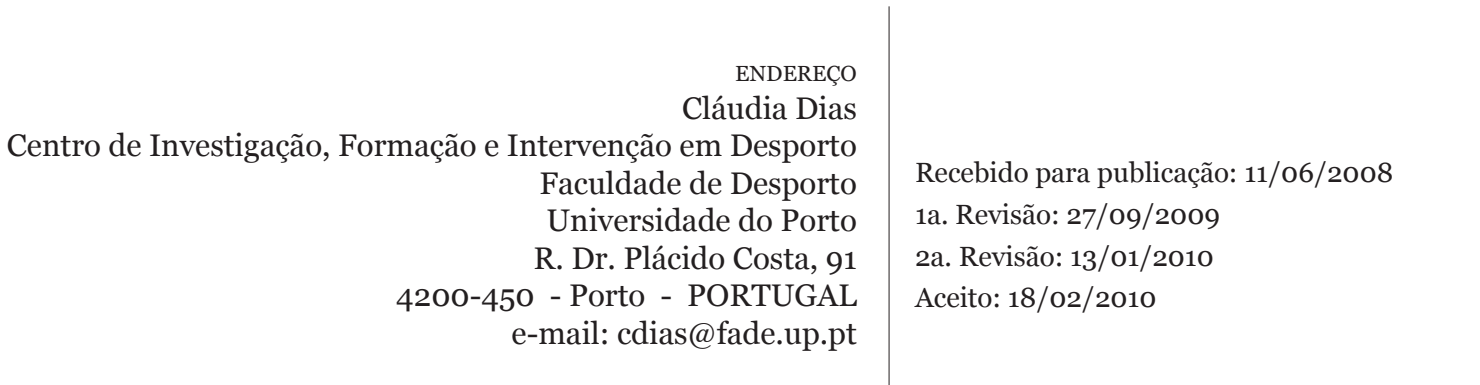

